\title{
Beliefs about medicines as mediators in medication adherence in type 2 diabetes
}

\author{
Maria da Graça Pereira PhD, Associate Professor ${ }^{1}$ (D) | Gabriela Ferreira MS $^{1}$ (D) । \\ José C. Machado PhD ${ }^{2}$ (D) Susana Pedras PhD $^{1}$
}

${ }^{1}$ School of Psychology, University of Minho, Campus de Gualtar, Braga, Portugal

${ }^{2}$ Institute of Social Sciences, University of Minho, Campus de Gualtar, Braga, Portugal

Correspondence

M. Graça Pereira, School of Psychology, University of Minho, Campus de Gualtar, Braga 4710-057, Portugal.

Email: gracep@psi.uminho.pt

Funding information

Foundation for Science and Technology of Portugal (FCT), Grant/Award Number: PTDC/ SAU-ESA/67581/2006

\begin{abstract}
Aims: This study analysed whether beliefs about medicines mediated the relationship between illness representations and medication adherence.

Background: Adherence to medication is required in diabetes treatment, contributing to decreased blood glycaemic levels. The knowledge and perception of patients about diabetes as well as the beliefs about medicines are considered to be key factors for medication adherence.
\end{abstract}

Design: The study used a cross-sectional design that included 387 patients recently diagnosed with type 2 diabetes.

Methods: Participants were assessed, between 2010 and 2013, and answered the Medication Adherence Scale, the Beliefs about Medicines Questionnaire, and the Brief Illness Perception Questionnaire.

Results: The results of the path analysis showed that beliefs about medicines had a mediating role on self-report medication adherence with the exception of beliefs about specific concerns with medicines. Therefore, both general beliefs and specific needs about medicines mediated the relationship between diabetes consequences and self-report medication adherence as well as between treatment control and self-report medication adherence. Needs about medicines mediated the relationship between personal control and self-report medication adherence.

Conclusion: Health professionals should target beliefs about medicines besides illness representations regarding medication adherence. The current study may help optimize adherence to medication in early-diagnosed type 2 diabetes patients.

\section{KEYWORDS}

beliefs, medication adherence, medicine, nursing, type 2 diabetes

\section{SUMMARY STATEMENT}

What is already known about this topic?

- Adherence to medication is a required self-care behaviour in type 2 diabetes treatment regimen to decrease blood glycaemic levels. 
never been studied in patients recently diagnosed with type 2 diabetes.

What this paper adds?

- Both general beliefs and specific needs about medicines mediated the relationship between diabetes consequences/treatment control and self-report medication adherence.

- Needs about medicines mediated the relationship between personal control and self-report medication adherence.

The implications of this paper:

- Health professionals should target beliefs about medicines besides illness representations regarding medication adherence.

- The current study may help optimize intervention regarding adherence to medication in early-diagnosed type 2 diabetes patients.

\section{1 | INTRODUCTION}

Diabetes affects about 422 million people worldwide and is considered a serious public health problem (Valdez, 2009; World Health Organization [WHO], 2017). In Portugal, a study conducted by the Portuguese Society of Diabetes (2016) revealed that, in the year of $2015,13.3 \%$ of the population had diabetes and $27.4 \%$ has prediabetes. The most common type of diabetes is type 2 diabetes mellitus (T2DM) corresponding to $90 \%$ of all cases (WHO, 2017).

Adherence to medication is required in T2DM treatment regimen and contributes to disease control being associated with decreased blood glycaemic levels (de Vries McClintock, Morales, Small, \& Bogner, 2016; Lin, Sun, Heng, Chew, \& Chong, 2017) and less hospitalization in newly diagnosed patients (Lin et al., 2017). Besides, medication adherence facilitates the control of other comorbidities associated with diabetes, such as hypertension and dyslipidaemia, and thereby contributes to a better quality of life decreasing the risk of microvascular and macrovascular complications, as well as mortality and health care costs (Kennedy-Martin, Boye, \& Peng, 2017; Polonsky \& Henry, 2016; Simpson, Lin, \& Eurich, 2016).

In spite of the advantages associated to medication adherence, it has been suggested that $30 \%$ to $50 \%$ of medicines prescribed for long-term illnesses are not taken as recommended (DiMatteo, Haskard-Zolnierek, \& Martin, 2012; Kane \& Robinson, 2010). Studies have shown that adherence to oral anti-diabetic medication ranges between 7\% and 64\% (Lee, Balu, Cobden, Joshi, \& Pashos, 2006). Also, a meta-analysis of 27 studies found that the prevalence of adherence to diabetes medication ranged between $38.5 \%$ and $93.1 \%$, and only $22.2 \%$ of the studies reported a prevalence of adherence equal or higher than $80 \%$ (Krass, Schieback, \& Dhippayom, 2015). Factors such as medication cost, depression, concerns with medication side effects, and forgetfulness have been described in the literature as modifiable predictors of medication adherence (Islam, Biswas, Bhuiyan, Mustafa, \& Islam, 2017; Krass et al., 2015). Moreover, a study found that patients new to diabetes therapy had a probability of $61 \%$ of being less adherent to diabetes medication (Kirkman et al., 2015). The knowledge and perception of patients about diabetes were also suggested to be key factors in adherence to medication (Islam et al., 2017).

The Common-Sense Model of Self-Regulation proposed by Leventhal, Meyer, and Nerenz (1980) explains how patients conceptualize their illness and develop coping strategies. The first stage of the model suggests how illness representations predict health behaviours, such as medication adherence (Brewer, Chapman, Brownlee, \& Leventhal, 2002; Mann, Ponieman, Leventhal, \& Halm, 2009; Ogden, 2012). Illness representations comprised the following beliefs: consequences (the extent to which patients are aware of the severity of the disease and its implications); timeline (patients' perception of the evolution and progress of the disease); personal and treatment control (the level of control that the patient perceives to have regarding the disease and its treatment, respectively); identity (the perception of disease symptoms); concerns (patients' worries about the disease); emotions (distress in dealing with the disease); and comprehension (the comprehension patients show regarding the disease; Figueiras et al., 2010; Scollan-Koliopoulos, O'Connnell, \& Walker, 2007; Searle, Norman, Thompson, \& Vedhara, 2007; Theunissen, de Reidder, Bensing, $\&$ Rutten, 2002).

Several studies have shown that illness representations predicted adherence to self-care behaviours in diabetes (Abubakari et al., 2011; Broadbent, Donkin, \& Stroh, 2011; Harvey \& Lawson, 2009). Hampson, Glasgow, and Foster (1995) found that beliefs about diabetes (perception of the severity of disease, efficacy of treatment, and diabetes control) were associated with $\mathrm{HbA1c}$, eating patterns, and physical and mental functioning. Illness representations such as patients' representations about the disease and treatment (Barnes, Moss-Morris, \& Kaufusi, 2004; Hampson et al., 1995; Horne, 2003; Horne, Weinman, \& Hankins, 1999; Mann et al., 2009; ScollanKoliopoulos et al., 2007; Searle et al., 2007), as well as representations of lower consequences, symptoms, and distress, and higher personal control over diabetes predicted adherence to medication (Abubakari et al., 2011; Aflakseir, 2012; Broadbent et al., 2011; Harvey \& Lawson, 2009, for a review). Patients that believe they have control over T2DM are more likely to adhere to self-care behaviours (Abubakari et al., 2011; Hampson et al., 1995).

Beliefs about medicines are considered a major factor in medication adherence (Horne \& Weinman, 1999; Mårdby, Åkerlind, \& Jörgensen, 2007). Studies with T2DM patients showed that adherence to medication was associated with stronger beliefs about the need of medicines and weaker beliefs about concerns with medicines and its harmful effects, in general (Polonsky \& Henry, 2016; Sweileh et al., 2014).

In patients with adrenal insufficiency, stronger needs of medicines have been associated with less personal control over the illness, while concerns were associated with lower perceived control over the treatment and lower illness coherence. Beliefs about the general harm of medicines, in turn, were associated with more cyclical timeline and stronger emotional representations (Tiemensma et al., 2014). Stronger needs about medicines for chronic pain were also associated with the perception of severe consequences, timeline, and emotional impact, as well as with lower personal control, while stronger 
concerns were associated with the perception of more symptoms, consequences, and emotional impact and lower illness coherence (Nicklas, Dunbar, \& Wild, 2010). Beliefs about the need of medicines mediated the relationship between illness perceptions (consequences and timeline) about asthma and adherence to medication (Horne \& Weinman, 2002).

The Extended Common-Sense Model proposes the inclusion of beliefs about medicines as mediators between illness representations and adherence (Horne \& Weinman, 2002), and this hypothesis has been tested in several disease samples. However, the mediator role of medication beliefs between illness representations regarding diabetes and medication adherence, in patients recently diagnosed with T2DM, has never been studied. Given the raising of T2DM prevalence worldwide, from a heuristic point of view, it is important to understand, earlier on, the beliefs that may contribute to medication adherence in order to prevent the severe complications that result from non-adherence, as well as the costs associated with it (Fukuda \& Mizobe, 2017; Lin et al., 2017). In fact, non-adherence to treatment, in the first year of diabetes, has been associated with increased incidence of microvascular complications: retinopathy (2.04), nephropathy (1.91), and neuropathy (1.83), respectively, by a hazard ratio (Fukuda \& Mizobe, 2017).

\section{2 | METHODS}

\section{1 | Aims}

Considering the Extended Common-Sense Model, therefore, this study aims to determine if beliefs about medicines mediated the relationship between illness representations and self-report medication adherence. Taking into consideration that personal and treatment control as well as comprehension are positive beliefs, we hypothesized they will be mediated by specific needs beliefs and that timeline, identity, concerns, consequences, and emotional response will be mediated by general beliefs regarding self-reported adherence to medication. We also hypothesized that specific concerns will not be associated with medication adherence in recently diagnosed patients, since concern beliefs about medicines were found to change over time in older adults, especially if the number of medicines increased over time and an adverse drug event has been reported (Shiyanbola, Farris, \& Chrischilles, 2013).

\section{2 | Design}

This study used a cross-sectional design.

\section{3 | Participants}

This study comprised a convenience sample of 387 Caucasian patients from the North of Portugal recently diagnosed with T2DM. The inclusion criteria included age above 18; be or have been diagnosed with T2DM no more than 1 year prior to data collection; and not receiving insulin injections, but only oral antidiabetic drugs (including also medication for hypertension and/or cholesterol).

\section{4 | Data collection}

Data collection took place in 40 health care centres of the northern region of Portugal, between 2010 and 2013. Patients were identified by their physicians, and if they met the inclusion criteria, they were contacted and invited to participate by the researcher. Data were collected during a patient's medical or nursing appointment. About $5 \%$ of the patients refused to participate in the study, but no differences in clinical and socio-economic characteristics were found between them and participants.

\section{5 | Measures}

\subsection{1 | Sociodemographic and Clinical Questionnaire}

This questionnaire included information about gender, age, years of education, employment status, marital status, and marriage duration. Besides, it comprises some clinical information about duration of diagnosis and family history of diabetes.

\subsection{2 | Medication Adherence Report Scale (MARS; Horne, 2001; Portuguese version of Pereira, Pedras, \& Machado, 2012)}

This instrument consisted of five items that assess medication adherence. Scores range between 5 and 25, and a high score indicates better medication adherence. The questionnaire showed an original Cronbach a of .70 (Horne, 2001). The Portuguese validation revealed a one-factor solution like the original version that explained $52.15 \%$ of the variance. In this sample, the a was .74.

\subsection{3 | Beliefs about Medicines Questionnaire (BMQ; Horne et al., 1999; Portuguese version of Pereira, Pedras, \& Machado, 2013)}

The instrument evaluates common beliefs that individuals have about the medication and includes two scales and four subscales: (a) the general beliefs scale that includes the subscale of harmful effects (four items) related with the harmful and addictive effects of drugs in general and the subscale of overuse (four items) related with the overprescribing of medication by physicians (b) and the specific beliefs scale that includes the subscale of specific needs (five items) related to the need to take the medication prescribed by the physician to maintain or improve health and the subscale of specific concerns (five items) related to negative side effects and long-term dangers of dependence and toxicity of the medication prescribed by the physician. General beliefs' score ranges between 5 and 40, while specific beliefs between 5 and 25. Higher scores indicate stronger beliefs in the respective dimension. In the original version (Horne et al., 1999), Cronbach alphas were .66 for the harmful effects, .80 
for overprescribing of medicines by physician, .74 for specific needs, and .80 for specific concerns. However, the Portuguese adapted version (Pereira et al., 2013) yielded three scales (with harmful and addictive effects together with the overprescribing by physicians under general beliefs) and not four as in the original version. The general beliefs scale explained $37.9 \%$ of the variance, the specific needs scale $26.9 \%$ of the variance, and the specific concerns scale explained $22.4 \%$ of the variance. In this sample, alphas were .76 for the general beliefs scale, .77 for the specific needs and .69 for specific concerns

\subsection{4 | Illness Perceptions Questionnaire-Brief (Brief IPQ; Broadbent, Petrie, Main, \& Weinman, 2006; Por- tuguese Version of Figueiras et al., 2010)}

This questionnaire comprises eight items, assessing the following illness representations: consequences, timeline, personal control, treatment control, identity (symptoms), concerns, comprehension, and emotional response. Higher scores correspond to more threatening illness perceptions. The scores of items 3, 4, and 7 are reversed. Alphas cannot be calculated, given that each scale includes only one item. Therefore, Pearson coefficient correlations were calculated, similarly to the original version. The correlations between the subscales, in this sample, were significant and ranged between .35 and .53 .

\section{6 | Ethical considerations}

The Ethics Committee of the North Regional Health Administration from Portugal approved this study. Participation was voluntary and participants signed an informed consent form for this purpose.

\section{7 | Data analysis}

In order to characterize the sample, means and standard deviations were calculated. Pearson coefficient correlations were performed to analyse the relationship between all the psychological variables. Path analysis was chosen as a model to test the hypothesized intercorrelations. For confirmatory factor analysis, Chou, Bentler, and Pentz (2000) and Myers, Ahn, and Jin (2011) suggested a sample size of 200 to 300 . Taking into consideration that the sample size included 387 patients, the sample was considered adequate. Model fit was assessed using model chi-square, goodness fit index (GFI), root mean square error approximate (RMSEA), and standardized root mean square residual (SRMR). Standardized beta coefficients ( $\beta$ ) were derived for each explanatory variable in order to allow comparing and estimating the relative importance of each measure. Adequate fit was defined as chi-square $P$ value over .05, GFI over .95, RMSEA below .07, and SRMR below .08 (Hooper, Coughlan, \& Mullen, 2008). Taking in consideration the $N: q$ rule, the current sample size is adequate (Jackson, 2003).

All standard statistical analyses were done using the IBM SPSS Statistics 22. The path analyses were performed in IBM SPSS Amos 22.

\section{3 | RESULTS}

\section{1 | Sample characteristics}

This study included 387 patients diagnosed with T2DM, with a mean age of 59.2 years. The majority of the sample was male (58.1\%), had only 4 years of education (67.2\%), and was married (99.2\%). Regarding the employment status, $37.1 \%$ of the patients were employed, and the remaining retired or unemployed. The majority of the sample had a family history of diabetes (61.0\%), and although all patients had been diagnosed in the year prior to the assessment, $60.1 \%$ were diagnosed in the last 6 months prior to the assessment.

\section{2 | Preliminary analyses}

Descriptive measures of all variables were calculated (Table 1). Overall, this sample presented good adherence to medication, moderate beliefs about the harmful effects of medicines, and concerns about their negative side effects as well as a high perception of the need of the prescribed medicines.

Table 1 presents the results of bivariate correlations between psychological variables. Higher adherence to medication was associated with weaker general beliefs about medicines and stronger needs about medicines. Higher adherence to medication was associated with the perception of greater consequences of diabetes, greater control over the disease and its treatment, greater symptoms as well as the perception of greater concern about diabetes, and the higher emotional impact of the disease. Illness representations of timeline and comprehension, as well as specific concerns about medicines, were not associated with medication adherence.

\subsection{Path analysis: the mediator role of beliefs about medicines}

All illness representations were significantly associated with medication adherence as well as the beliefs about medicines (three subscales as mediators) were included. However, since specific concerns did not have the expected mediation effect, it was dropped. The final model showed an acceptable adjustment: CFI $=.926$, RMSEA $=.072$, and $\mathrm{SRMR}=.047$. The indirect effect of the representations about diabetes consequences on medication adherence was mediated by specific needs and general beliefs (indirect effect $=.019 ; P=.388 ; 95 \% \mathrm{Cl}=$ -0.024 to 0.066 ). Also, the indirect effect of patients' representation about diabetes' treatment control on medication adherence was mediated by specific needs and general beliefs (indirect effect $=-.099$; $P=.001 ; 95 \% \mathrm{Cl}=-0.169$ to -0.045$)$. The indirect effect of patients' representation about diabetes' personal control on medication adherence was mediated by specific needs (indirect effect $=.029 ; P=.005$; $95 \% \mathrm{Cl}=0.007-0.065)$. Finally, concerns about T2DM were positively associated with medication adherence $(\beta=.170, P<.001)$. Particularly, higher concerns were associated with higher adherence to medication (Figure 1). 
TABLE 1 Bivariate correlations between psychological variables

\begin{tabular}{|c|c|c|c|c|c|c|c|c|c|c|c|c|}
\hline Variables & 1 & 2 & 3 & 4 & 5 & 6 & 7 & 8 & 9 & 10 & 11 & 12 \\
\hline 1. MARS & - & & & & & & & & & & & \\
\hline 2.BMQ_general & $-.13^{* *}$ & - & & & & & & & & & & \\
\hline 4.BMQ_concerns & -.04 & $.47^{* * *}$ & .03 & - & & & & & & & & \\
\hline 5. IPQ1 & $.12^{*}$ & $.26^{* * *}$ & $.16^{* *}$ & $.43^{* * *}$ & - & & & & & & & \\
\hline 7. IPQ3 & $-.14^{* *}$ & .09 & .05 & -.03 & .02 & -.002 & - & & & & & \\
\hline 8. IPQ4 & $-.25^{* * *}$ & $.14^{* *}$ & $-.28^{* * *}$ & $.17^{* * *}$ & $.18^{* * *}$ & $-.16^{* *}$ & $.22^{* * *}$ & - & & & & \\
\hline 9. IPQ5 & $.10^{*}$ & $.27^{* * *}$ & .08 & $.37^{* * *}$ & $.51^{* * *}$ & $.13^{*}$ & $-.12^{*}$ & .09 & - & & & \\
\hline 10. IPQ6 & $.19^{* * *}$ & $.14^{* *}$ & $.15^{* *}$ & $.38^{* * *}$ & $.40^{* * *}$ & $.18^{* * *}$ & $-.13^{*}$ & -.05 & $.25^{* * *}$ & - & & \\
\hline SD & 2.55 & 6.14 & 4.05 & 4.58 & 3.18 & 3.19 & 2.93 & 2.08 & 2.15 & 3.49 & 3.26 & 3.01 \\
\hline
\end{tabular}

Abbreviations: BMQ_concerns, beliefs about the concerns with medication; BMQ_general, general beliefs about medicines; BMQ_needs, beliefs about the need to take medication; IPQ1, consequences; IPQ2, timeline; IPQ3, personal control; IPQ4, treatment control; IPQ5, identity; IPQ6, concerns; IPQ7, comprehension; IPQ8, emotional response; M, mean; MARS, Medication Adherence Report Scale; SD, standard deviation.

${ }^{*} P<.05$.

${ }^{* *} P<.01$.

${ }^{* * *} P<.001$.

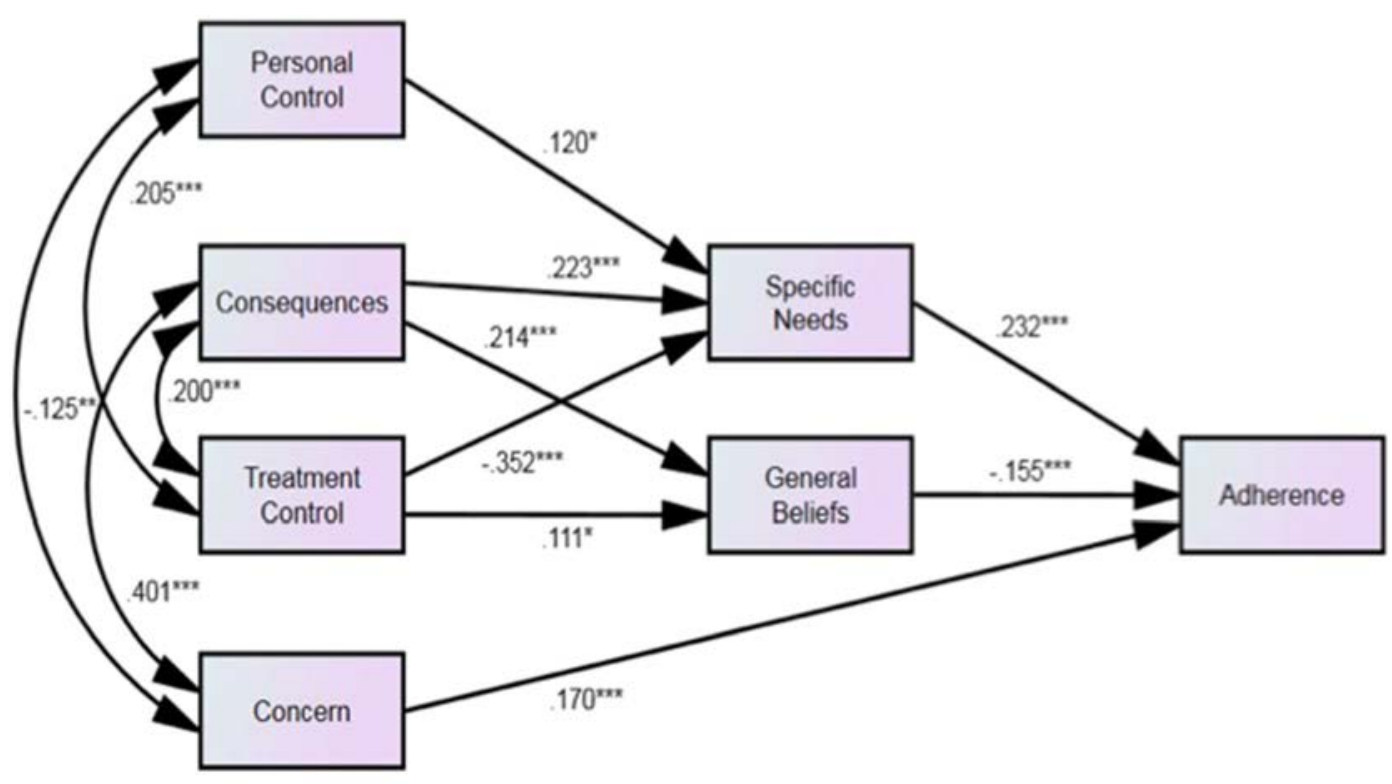

${ }^{*} p<.05 ;{ }^{* *} p<.01 ;{ }^{* * *} p<.001$

Fit indices: $\chi 2(9)=26.9(\mathrm{p}=.001) ; \chi 2 / \mathrm{df}=2.99 ; \mathrm{GFI}=.981 ; \mathrm{CFI}=.926 ; \mathrm{SRMR}=.047$;

RMSEA $=.072 ;$ CI95\% $=[.042 ; .104]$

$\mathrm{C} 195 \%=$ Bootstrap bias-corrected confidence interval at $95 \%$ (2000 samples)

FIGURE 1 Path analysis with standardized direct effects and correlations

\section{4 | DISCUSSION}

The aim of this study was to determine if beliefs about medicines mediated the relationship between illness representations about
T2DM and adherence to medication, based on the Extended Common-Sense Model (Horne \& Weinman, 2002).

The results of path analysis revealed that both general beliefs and specific needs about medicines mediated the relationships between 
illness representations of diabetes consequences and adherence to medication and between treatment control and medication adherence. Indeed, specific needs about medicines were found to mediate between consequences and medication adherence in patients with asthma (Horne \& Weinman, 2002). Also, stronger needs about medicines have been associated with severe illness consequences in patients with adrenal insufficiency (Tiemensma et al., 2014), chronic pain (Nicklas et al., 2010), and asthma (Horne \& Weinman, 2002).

Contrary to previous findings, which suggested that medication adherence is associated with representations of lower consequences (Aflakseir, 2012; Broadbent et al., 2011), in the present study, medication adherence was associated with the perception of greater consequences of T2DM. Therefore, it seems plausible that, if patients believe that the disease may have a greater impact on their lives, they will adhere more to the medication, in order to prevent or reduce short- and long-term consequences. A qualitative study conducted with T2DM patients found that patients considered avoiding long-term complications and control glycaemia as the main advantages of taking oral antidiabetic drugs (Guénette et al., 2015). Also, the perception of the impact of T2DM may lead to the strengthening of beliefs about the need to take the prescribed medicines. Previous studies have found that medication adherence was associated with higher treatment control over diabetes (Barnes et al., 2004; Hampson et al., 1995; Horne, 2003; Horne et al., 1999; Mann et al., 2009; Scollan-Koliopoulos et al., 2007; Searle et al., 2007), corroborating the results of the present study. , it makes intuitive sense that patients will adhere more to medication, if they believe they have greater control over the treatment, as well as stronger convictions concerning the need of medicines.

Regarding the mediator role of general beliefs about medicines, the literature has found that general beliefs were associated with lower adherence to medication (Grant, Devita, Singer, \& Meigs, 2003; Pereira et al., 2013; Sweileh et al., 2014). Nevertheless, other studies have suggested that patients make an assessment of costs and benefits regarding medication adherence (Horne et al., 1999; Horne \& Weinman, 1999). In this cost-benefits assessment, patients balance the harmful effects of medication with the need to take it in order to maintain or improve their health. Our hypothesis that specific concerns were not associated with adherence was confirmed, which may be explained by the fact that recently diagnosed patients had not yet time to experience the negative side effects of medication and these beliefs seem to change over time (Shiyanbola et al., 2013).

Finally, specific needs about medicines mediated the relationship between personal control over diabetes and medication adherence. Medication adherence has also been associated with higher personal control over diabetes (Broadbent et al., 2011), while needs about medicines have been associated with less personal control in patients with adrenal insufficiency (Tiemensma et al., 2014) and chronic pain (Nicklas et al., 2010), corroborating the results of the present study.

More symptoms, greater comprehension, and emotional response were not associated with adherence to medication and, thus, did not confirm our hypothesis. Indeed, concerns about T2DM were associated with higher adherence to medication but were not mediated by beliefs about medicines. Broadbent et al (2011) found that medication adherence was associated with lower distress. It seems plausible that those patients who are concerned with T2DM, and have been recently diagnosed, would adhere to medication, in order to reduce the likelihood of developing severe complications later, regardless of their beliefs about medication.

This study emphasized the importance of cognitive variables such as illness representations and beliefs about medicines on medication adherence. More specifically, the results showed that beliefs about medicines have a mediator role in the relationship between cognitive illness representations and medication adherence. Therefore, the results partially corroborate the Extended Common-Sense Model (Horne \& Weinman, 2002). However, a meta-analysis conducted by Brandes and Mullan (2014) concluded that the relationships between illness representations and adherence are weak and the latter might not be the best predictors of adherence in chronically ill patients. In addition, the authors suggested that the Common-Sense Model is useful to understand adherence, rather than to predict it (Brandes \& Mullan, 2014). Notwithstanding, Phillips, Cohen, Burns, Abrams, and Renninger (2016) tested an Extended Common-Sense Model including initiation and maintenance factors and found that the degree of automatic behavioural repetition was a better predictor of adherence to medication and physical activity, in T2DM patients than beliefs and experiences with the treatment. The authors also suggested that beliefs might play a key role in the beginning of the treatment (Phillips et al., 2016), as is the case in recently diagnosed T2DM patients.

Although beliefs about the timeline and comprehension of the disease were not associated with adherence, symptoms and emotional response were indeed correlated with adherence. The fact that emotional response was not associated with medication adherence may be related to the low number of symptoms patients may present, when recently diagnosed, or to the fact that patients are still learning about the consequences of diabetes and in the process of adapting to the disease not being able to have a strong emotional response to diabetes. In a longitudinal study with diabetic patients, Lawson, Bundy, and Harvey (2008) found emotional representations to decrease within 2 years after the diagnosis while illness coherence increased. Also, in a sample of patients with chronic kidney disease, Tasmoc, Hogas, and Covic (2013) found that emotional representations were significantly less intense at follow-up (6 years) than at baseline.

The results also partially confirmed the Necessity-Concerns Framework, given that the beliefs of concerns about medicines were not associated with medication adherence, while specific needs and general beliefs were. These non-significant results may be due to the characteristics of the sample that comprised patients recently diagnosed with T2DM. We hypothesize that patients did not have time yet to be concerned with their medications' negative side effects and the dangers of dependence and toxicity. Rather than the specific concerns, the results highlight the negative role of the general beliefs as being associated with medication adherence, like expected (Sweileh et al., 2014), since the medication prescription does not occur in a vacuum (Horne et al., 2013), ie, patients already have their beliefs about the medicines in general, and these will influence patients' evaluation about the prescribed medicines as well asadherence to medication, for T2DM. 
The fact that the model tested was theoretically driven provides meaningful interpretation of the relationships found. Nonetheless, future studies should incorporate objective measures of medication adherence and use longitudinal studies to analyse the impact of beliefs about disease and medicines, over time, in T2DM patients regarding adherence to medication and adjustment to illness, in order to identify the different sets of beliefs determinant for medication adherence, in each phase of the illness. It will be important also to compare the results of the present study with patients that have been diagnosed for a longer period of time as well as with patients taking insulin. Partner's beliefs about medication should be addressed in future studies, since spouses are often actively involved in T2DM treatment (Pereira, Pedras, Ferreira, \& Machado, 2017; Stephens, Rook, Franks, Khan, \& lida, 2010).

Future research should also explore intentional non-adherence (eg, patients do not take medicines because of their concerns with negative side effects) versus non-intentional (eg, forget to take medicines) and the underlying beliefs (Fukuda \& Mizobe, 2017; Horne et al., 2013) as well as taking into account other theoretical frameworks such as the theory of planned behaviour in predicting medication adherence (Brandes \& Mullan, 2014).

\section{1 | Limitations}

The present study has limitations that should be taken into consideration, particularly the cross-sectional nature of the design that does not allow for causality inferences and the fact that adherence to medication was assessed through a self-report questionnaire.

\section{5 | CONCLUSION}

The results of the present study suggest that future interventions aiming to promote medication adherence, in T2DM, should include the beliefs about medicines and illness representations. According to this study, the set of beliefs that are important in adherence to medication in early-diagnosed patients are personal and treatment control, consequences, and concerns with T2DM, as well as specific needs and general beliefs about medicines. Interventions to optimize adherence should be tailored to patients' needs, considering their perceptions about the illness and the prescribed medicines, as well as patients' skills and resources. Health care providers should discuss with patients, their beliefs and preferences, in order to promote the development of strategies for diabetes management in their daily lives. It is also important to assess the type of adherence when determining the psychosocial factors that are involved. Besides illness representations and beliefs about medicines, it is important to study the impact of strategies to promote adherence such as reminders and dose organizers in patients with unintentional non-adherence (McSharry, McGowan, Farmer, \& French, 2016). Such a differentiation may help optimize interventions to the particular type of non-adherence exhibited by the patient before it becomes established, during the course of diabetes. Interventions to promote adherence that present different rates of effectiveness, such as reminders by telephone done by health care providers, health coaching, educational interventions, and integrated care managers (Kennedy-Martin et al., 2017), should therefore take into consideration the type of non-adherence and be specific to the patient's needs. Finally, health policies should also facilitate patient's adherence in early diagnosed T2DM before complications settled in.

\section{FUNDING}

This study is part of a research project PTDC/SAU-ESA/67581/2006 supported by the Foundation for Science and Technology of Portugal (FCT).

\section{CONFLICT OF INTEREST}

The authors declare that there is no conflict of interest.

\section{AUTHORSHIP STATEMENT}

All listed authors meet the authorship criteria and all authors are in agreement with the content of the manuscript. MGP was responsible for the study design, data analysis and interpretation, manuscript preparation, and manuscript review. GF and SP collected the data and were responsible for data analysis and interpretation and manuscript preparation. JCM was responsible for the statistical analysis, data analysis and interpretation, and manuscript preparation. All authors approved the final version for submission.

\section{ORCID}

Maria da Graça Pereira (D) https://orcid.org/0000-0001-7987-2562

Gabriela Ferreira (D) https://orcid.org/0000-0003-0993-5614

José C. Machado (D) https://orcid.org/0000-0003-2552-118X

Susana Pedras (D) https://orcid.org/0000-0001-5771-562X

\section{REFERENCES}

Abubakari, A. R., Jones, M. C., Lauder, W., Kirk, A., Anderson, J., \& Devendra, D. (2011). Associations between knowledge, illness perceptions, self-management and metabolic control of type 2 diabetes among African and European-origin patients. Journal of Nursing and Healthcare of Chronic Illness, 3, 245-256. https://doi.org/10.1111/ j.1752-9824.2011.01098.x

Aflakseir, A. (2012). Role of illness and medication perceptions on adherence to medication in a group of Iranian patients with type 2 diabetes. Journal of Diabetes, 4, 243-247. https://doi.org/10.1111/ j.1753-0407.2012.00183.x

Barnes, L., Moss-Morris, R., \& Kaufusi, M. (2004). Illness beliefs and adherence in diabetes mellitus: A comparison between Tongan and European patients. The New Zealand Medical Journal, 117(743), 1-9.

Brandes, K., \& Mullan, B. (2014). Can the common-sense model predict adherence in chronically ill patients? A meta-analysis. Health Psychology Review, 8, 129-153. https://doi.org/10.1080/17437199.2013.820986

Brewer, N. T., Chapman, G. B., Brownlee, S., \& Leventhal, E. A. (2002). Cholesterol control, medication adherence and illness cognition. British Journal of Health Psychology, 7, 433-447. https://doi.org/10.1348/ 135910702320645408 
Broadbent, E., Donkin, L., \& Stroh, J. C. (2011). Illness and treatment perceptions are associated with adherence to medications, diet, and exercise in diabetic patients. Diabetes Care, 34, 338-340. https://doi. org/10.2337/dc10-1779

Broadbent, E., Petrie, K. J., Main, J., \& Weinman, J. (2006). The Brief Illness Perception Questionnaire (B-IPQ). Journal of Psychosomatic Research, 60, 631-637. https://doi.org/10.1016/j.jpsychores.2005.10.020

Chou, C. P., Bentler, P. M., \& Pentz, M. A. (2000). A two-stage approach to multilevel structural equation models: Application to longitudinal data. In T. D. Little, K. U. Schnabel, \& J. Baumert (Eds.), Modeling longitudinal and multilevel data, practical issues, applied approaches, and specific examples (pp. 33-49). Mahwah, New Jersey: Lawrence Erlbaum Associates.

de Vries McClintock, H. F., Morales, K. H., Small, D. S., \& Bogner, H. R. (2016). Patterns of adherence to oral hypoglycemic agents and glucose control among primary care patients with type 2 diabetes. Behavioral Medicine, 42, 63-71. https://doi.org/10.1080/08964289.2014. 904767

DiMatteo, M. R., Haskard-Zolnierek, K. B., \& Martin, L. R. (2012). Improving patient adherence: $A$ three-factor model to guide practice. Health Psychology Review, 6, 74-91. https://doi.org/10.1080/17437199. 2010.537592

Figueiras, M., Marcelino, D., Claudino, A., Cortes, M., Maroco, J., \& Weinman, J. (2010). Patients' illness schemata of hypertension: The role of beliefs in the choice of treatment. Psychology \& Health, 25, 507-517. https://doi.org/10.1080/08870440802578961

Fukuda, H., \& Mizobe, M. (2017). Impact of nonadherence on complication risks and healthcare costs in patients newly-diagnosed with diabetes. Diabetes Research \& Clinical Practice, 123, 55-62. https://doi.org/ 10.1016/j.diabres.2016.11.007

Grant, R. W., Devita, N. G., Singer, D. E., \& Meigs, J. B. (2003). Polypharmacy and medication adherence in patients with type 2 diabetes. Diabetes Care, 26, 1408-1412. https://doi.org/10.2337/ diacare.26.5.1408

Guénette, L., Lauzier, S., Guillaumie, L., Giguère, G., Grégoire, J.-P., \& Moisan, J. (2015). Patients' beliefs about adherence to oral antidiabetic treatment: A qualitative study. Patient Preference and Adherence, 9, 413-420. https://doi.org/10.2147/PPA.S78628

Hampson, S. E., Glasgow, R. E., \& Foster, L. S. (1995). Personal models of diabetes among older adults: Relationship to self-management and other variables. Diabetes Educator, 21, 300-307. https://doi.org/ 10.1177/014572179502100407

Harvey, J. N., \& Lawson, V. L. (2009). The importance of health belief models in determining self-care behavior in diabetes. Diabetic Medicine, 26, 5-13. https://doi.org/10.1111/j.1464-5491.2008.02628.x

Hooper, D., Coughlan, J., \& Mullen, M. (2008). Structural equation modelling: Guidelines for determining model fit. The Electronic Journal of Business Research Methods, 6(1), 53-60.

Horne, R. (2001). Non-adherence to medication: Causes and implications for care. In P. Gard (Ed.), A behavioural approach to pharmacy practice (pp. 111-130). Oxford: Blackwell.

Horne, R. (2003). Treatment perceptions and self-regulation). In L. D. Cameron, \& H. Leventhal (Eds.), The self-regulation of health and illness behavior (pp. 138-154). London: Routledge.

Horne, R., Chapman, S. C. E., Parham, R., Freemantle, N., Forbes, A., \& Cooper, V. (2013). Understanding patients' adherence-related beliefs about medicines prescribed for long-term conditions: A meta-analytic review of the necessity-concerns framework. PLOS ONE, 8, e80633. https:// doi.org/10.1371/journal.pone.0080633

Horne, R., \& Weinman, J. (1999). Patients' beliefs about prescribed medicines and their role in adherence to treatment in chronic physical illness. Journal of Psychosomatic Research, 47, 555-567. https://doi. org/10.1016/S0022-3999(99)00057-4

Horne, R., \& Weinman, J. (2002). Self-regulation and self-management in asthma: Exploring the role of illness perceptions and treatment beliefs in explaining non-adherence to preventer medication. Psychology \& Health, 17, 17-32. https://doi.org/10.1080/08870440290001502

Horne, R., Weinman, J., \& Hankins, M. (1999). The Beliefs about Medicines Questionnaire: The development and evaluation of a new method for assessing the cognitive representation of medication. Psychology \& Health, 14, 1-24. https://doi.org/10.1080/08870449908407311

Islam, S. M. S., Biswas, T., Bhuiyan, F. A., Mustafa, K., \& Islam, A. (2017). Patients' perspective of disease and medication adherence for type 2 diabetes in an urban area in Bangladesh: A qualitative study. BMC Research Notes, 10, 1-8. https://doi.org/10.1186/s13104-017-2454-7

Jackson, D. L. (2003). Revising sample size and number of parameters estimates: Some support for the N:q hypothesis. Structural Equation Modeling: A Multidisciplinary Journal, 10, 128-141. https://doi.org/ 10.1207/S15328007SEM1001_6

Kane, S. V., \& Robinson, A. (2010). Review article: Understanding adherence to medication in ulcerative colitis-Innovative thinking and evolving concepts. Alimentary Pharmacology \& Therapeutics, 32, 1051-1058. https://doi.org/10.1111/j.1365-2036.2010.04445.x

Kennedy-Martin, T., Boye, K. S., \& Peng, X. (2017). Cost of medication adherence and persistence in type 2 diabetes mellitus: $A$ literature review. Patient Preference and Adherence, 11, 1103-1117. https://doi. org/10.2147/PPA.S136639

Kirkman, M. S., Rowan-Martin, M. T., Levin, R., Fonseca, V. A., Schmittdiel, J. A., Herman, W. H., \& Aubert, R. E. (2015). Determinants of adherence to diabetes medications: Findings from a large pharmacy claims database. Diabetes Care, 38, 604-609. https://doi.org/ $10.2337 / \mathrm{dc} 14-2098$

Krass, I., Schieback, P., \& Dhippayom, T. (2015). Systematic review or metaanalysis adherence to diabetes medication: A systematic review. Diabetic Medicine, 32, 725-737. https://doi.org/10.1111/dme.12651

Lawson, V. L., Bundy, C., \& Harvey, J. N. (2008). The development of personal models of diabetes in the first 2 years after diagnosis: A prospective longitudinal study. Diabetic Medicine, 25, 482-490. https://doi.org/10.1111/j.1464-5491.2008.02394.x

Lee, W. C., Balu, S., Cobden, D., Joshi, A. V., \& Pashos, C. L. (2006). Prevalence and economic consequences of medication adherence in diabetes: A systematic literature review. Managing Care Interface, 19(7), 31-41.

Leventhal, H., Meyer, D., \& Nerenz, D. (1980). The common sense representation of illness danger. In S. Rachman (Ed.), Contributions to medical psychology (pp. 7-30). Oxford: Pergamon Press.

Lin, L.-K., Sun, Y., Heng, B. H., Chew, D. E. K., \& Chong, P.-N. (2017). Medication adherence and glycemic control among newly diagnosed diabetes patients. BMJ Open Diabetes Research \& Care, 5, e000429. https://doi.org/10.1136/bmjdrc-2017-000429

Mann, D. M., Ponieman, D., Leventhal, H., \& Halm, E. A. (2009). Predictors of adherence to diabetes medications: The role of disease and medication beliefs. Journal of Behavioral Medicine, 32, 278-284. https://doi. org/10.1007/s10865-009-9202-y

Mårdby, A., Åkerlind, I., \& Jörgensen, T. (2007). Beliefs about medicines and self-reported adherence among pharmacy clients. Patient Education and Counseling, 69, 158-164. https://doi.org/10.1016/j. pec.2007.08.011

McSharry, J., McGowan, L., Farmer, A. J., \& French, D. P. (2016). Perceptions and experiences of taking oral medications for the treatment of Type 2 diabetes mellitus: A systematic review and meta-synthesis of 
qualitative studies. Diabetic Medicine, 33, 1330-1338. https://doi.org/ 10.1111/dme.13152

Myers, N., Ahn, S., \& Jin, Y. (2011). Sample size and power estimates for a confirmatory factor analytic model in exercise and sport: A Monte Carlo approach. Research Quarterly for Exercise and Sport, 82, 412-423. https://doi.org/10.1080/02701367.2011.10599773

Nicklas, L. B., Dunbar, M., \& Wild, M. (2010). Adherence to pharmacological treatment of non-malignant chronic pain: The role of illness perceptions and medication beliefs. Psychology \& Health, 25, 601-615. https://doi.org/10.1080/08870440902783610

Ogden, J. (2012). Health psychology: A textbook (5th ed.). United Kingdom: Open University Press.

Pereira, M. G., Pedras, S., Ferreira, G., \& Machado, J. C. (2017). Family and couple variables regarding adherence in type 2 diabetes patients in the initial stages of the disease. Journal of Marital and Family Therapy. Epub ahead of print, 45, 134-148. https://doi.org/10.1111/jmft.12281

Pereira, M. G., Pedras, S., \& Machado, J. C. (2012). Adaptação do questionário de adesão à medicação numa amostra de pacientes Portugueses com Diabetes Tipo 2 [Adaptation of the questionnaire of adherence to medication in a Portuguese sample of patients with type 2 Diabetes]. Revista da Sociedade Brasileira de Psicologia Hospitalar, 15(2), 148-166. Retrieved from:. http://pepsic.bvsalud.org/pdf/ rsbph/v15n2/v15n2a11.pdf

Pereira, M. G., Pedras, S., \& Machado, J. C. (2013). Validation of the questionnaire of beliefs towards medicines in type 2 diabetic patients. Psicologia: Teoria e Pesquisa, 29, 229-236. https://doi.org/10.1590/ S0102-37722013000200012

Phillips, L. A., Cohen, J., Burns, E., Abrams, J., \& Renninger, S. (2016). Self-management of chronic illness: The role of 'habit' versus reflective factors in exercise and medication adherence. Journal of Behavioral Medicine, 39, 1076-1091. https://doi.org/10.1007/ s10865-016-9732-z

Polonsky, W. H., \& Henry, R. R. (2016). Poor medication adherence in type 2 diabetes: Recognizing the scope of the problem and its key contributors. Patient Preference and Adherence, 10, 1299-1307. https://doi.org/ 10.2147/PPA.S106821

Portuguese Society of Diabetes [PSD] (2016). Diabetes: Facts and numbers. The year of 2015. Available from: http://www.spd.pt/images/ bolsas/dfn2015.pdf [Accessed 3rd April 2017].

Scollan-Koliopoulos, M., O'Connnell, K., \& Walker, E. A. (2007). Legacy of diabetes and self-care behavior. Research in Nursing \& Health, 30, 508-517. https://doi.org/10.1002/nur.20208

Searle, A., Norman, P., Thompson, R., \& Vedhara, K. (2007). Illness representations among patients with DMT2 and their partners: Relationships with self-management behaviors. Journal of Psychosomatic Research, 63, 175-184. https://doi.org/10.1016/j.jpsychores.2007.02.006
Shiyanbola, O. O., Farris, K. B., \& Chrischilles, E. (2013). Concern beliefs in medications: Changes over time and medication use factors related to a change in beliefs. Research in Social and Administrative Pharmacy, 9, 446-457. https://doi.org/10.1016/j.sapharm.2012.07.003

Simpson, S. H., Lin, M., \& Eurich, D. T. (2016). Medication adherence affects risk of new diabetes complications: A cohort study. The Annals of Pharmacotherapy, 50, 741-746. https://doi.org/10.1177/ 1060028016653609

Stephens, M. A., Rook, K. S., Franks, M. M., Khan, C., \& lida, M. (2010). Partners use of social control to improve diabetic patients dietary adherence. Families, Systems, \& Health, 28, 199-208. https://doi.org/ 10.1037/a0020513

Sweileh, W. M., Zyoud, S. H., Nab'a, R. J. A., Deleq, M. I., Enaia, M. I., Nassar, S. M., \& Al-Jabi, S. W. (2014). Influence of patients' disease knowledge and beliefs about medicines on medication adherence: Findings from a cross-sectional survey among patients with type 2 diabetes mellitus in Palestine. BioMed Central Public Health, 14, 94. https://doi.org/10.1186/1471-2458-14-94

Tasmoc, A., Hogas, S., \& Covic, A. (2013). A longitudinal study on illness perceptions in hemodialysis patients: Changes over time. Archives of Medical Science, 31, 831-836. https://doi.org/10.5114/aoms. 2013.38678

Theunissen, N. C., de Reidder, D. T. D., Bensing, J. M., \& Rutten, G. (2002). Manipulation of patient-provider interaction: Discussing illness representations or action plans concerning adherence. Patient Education and Counseling, 51, 247-258. https://doi.org/10.1016/S07383991(02)00224-0

Tiemensma, J., Andela, C. D., Pereira, A. M., Romijn, J. A., Biermasz, N. R., \& Kaptein, A. A. (2014). Patients with adrenal insufficiency hate their medication: Concerns and stronger beliefs about the necessity of hydrocortisone intake are associated with more negative illness perceptions. Journal of Clinical Endocrinology \& Metabolism, 99, 3668-3676. https://doi.org/10.1210/jc.2014-1527

Valdez, R. (2009). Detecting undiagnosed type 2 diabetes: Family history as a risk factor and screening tool. Journal of Diabetes Science and Technology, 3, 722-726. https://doi.org/10.1177/193229680900300417

World Health Organization (2017). Diabetes: Fact sheet. Accessed on December 28, 2017 at http://www.who.int/mediacentre/factsheets/ fs312/en/

How to cite this article: Pereira MG, Ferreira G, Machado JC, Pedras S. Beliefs about medicines as mediators in medication adherence in type 2 diabetes. Int J Nurs Pract. 2019;25: e12768. https://doi.org/10.1111/ijn.12768 